DOI 10.37882/2223-2982.2021.06.03

\title{
ИННОВАЦИОННЫЙ КОНТЕКСТ ИСПОЛЬЗОВАНИЯ ИНФОРМАЦИОННЫХ ТЕХНОЛОГИЙ В ПЕДАГОГИЧЕСКОЙ ДИАГНОСТИКЕ
}

\section{INNOVATIVE CONTEXT OF THE USE INFORMATION TECHNOLOGIES IN PEDAGOGICAL DIAGNOSTICS}

\section{R. Belalov}

Summary: The article reveals the features of the implementation of information technologies in pedagogical diagnostics. The author defines the specifics of the content of pedagogical diagnostics in the context of modern informatization and digitalization of society. At the same time, the main purpose of the study is to identify the specifics of the use of information technologies in the diagnostic process. The objectives of the study in the context of the use of information technologies in the diagnostic process are defined. The author points out the innovative aspect of the inclusion of information technologies in the process of pedagogical diagnostics, the need to take into account and select methods according to diagnostic parameters. It also summarizes the experience of domestic and foreign research in the field of computerization of diagnostic techniques.

Keywords: pedagogical diagnostics, information technologies, didactic methods, innovative product, scientific and methodological support, information competencies, structure of information competence.

\author{
Белалов Рашед Маазович \\ к.п.н., ФГБОУВО «Чеченский государственный \\ педагогический университет» \\ 1961rashi@mail.ru
}

Аннотация: В статье раскрываются особенности реализации информационных технологий в педагогической диагностике. Автор определяет специфику содержания педагогической диагностики в контексте современной информатизации и цифровизации общества. При этом основной целью исследования определяется выявление специфики использования информационных технологий в процессе диагностики. Определены задачи исследования в контексте применения информационных технологий в диагностическом процессе.

Автор указывает на инновационный аспект включения информационных технологий в процесс педагогической диагностики, необходимость учета и подбора методик соответственно диагностическим параметрам. Также обобщается опыт отечественных и зарубежных исследований в области компьютеризации диагностических методик.

Ключевые слова: педагогическая диагностика, информационные технологии, дидактические методы, инновационный продукт, научно- методическое сопровождение, информационные компетенции, структура информационной компетенции.
A ктуальность: на настоящий момент современная система образования находится на этапе трансформации- современные образовательные технологии приобретают инновационный контекст. Все более актуализируются дистанционные формы, с применением цифровых технологий, компьютерных средств обучения. С одной стороны, данные рамки поставлены перед образовательной системой негативными мировыми событиями - пандемией, ее последствиями, с другой - расширяются возможности обучения для всех участников образовательного процесса. Педагоги могут осуществлять профессиональную деятельность на различных образовательных платформах, находить новые направления развития. Обучающиеся в то же время могут выбирать альтернативные формы и средства образования, обучаться в различных образовательных учреждениях, выбирать педагогов, корректировать образовательные программы. Поэтому образовательная практика носит опережающий характер, ориентированный на зону ближайшего развития обучающихся. Однако, для определения зоны ближайшего развития, перспектив обучения и разработки индивидуальных траекторий развития и образования необходима педагогическая диагностика, реализуемая при помощи как традиционных, так и инновационных технологий.

Именно поэтому целью нашего исследования является выявление специфики использования информационных технологий в процессе педагогической диагностики.

Для достижения цели нами был поставлен ряд задач:

1. Определение содержания информационных технологий в педагогической диагностике;

2. Выявление необходимости включения информационных технологий в педагогическую диагностику;

3. Актуализация использования в педагогической диагностике информационных технологий.

В качестве основных методов был использован теоретический анализ литературы, сравнительный анализ данных педагогических исследований различных авторов. 
На начальном этапе исследования необходимо определить понятие и содержание информационных технологий. Это является необходимым условием их внедрения, т.к. структура и содержание определяется дидактическими принципами, закономерностями организации педагогического процесса, требованиями к педагогической диагностике, а также содержанием международных, российских и региональных законодательных актов в системе образования.

«Педагогическая диагностика является составляющей учебного процесса, система педагогической диагностики является подсистемой педагогической системы, и понятие педагогическое проектирование в полном объеме касается проектирования системы педагогической диагностики.» $[3,478]$ Системный характер диагностики важен и при включении информационных технологий, т.к. обуславливает структуру и содержание диагностических методик. Именно поэтому необходимо определить, чем же отличается внедрение информационных технологий в педагогику от других социальных и научных систем. Во-первых, необходимо упомянуть ФГОСы, которые предъявляют повышенные требования к качеству и результатам образования. «Речь идет и о необходимости анализировать не только саму информацию на предмет ее полезности, а также сами источники, которые могут представлять различные уровни истинности, важности и объективности» $[1,84]$ Диагностировать необходимо именно само содержание критерия- знание, педагогические особенности, факторы, влияющие на образовательный процесс, а не оценки и аналитические данные, которые могут сопровождать процесс первоначальной диагностики, тем самым снижая объективность информации. Информатизация процесса диагностики позволяет избежать субъективных суждений и оценок и анализировать данные, полученные в ходе программной обработки.

Исходя из этого, необходимо отметить, что традиционные технологии диагностики, а затем воспитания и образования не будут столь эффективны и обретут большую ценность в дополнении информационными, инновационными. Г.И. Кириллова отмечает, что «внедрение информационных технологий должно обеспечить педагога исчерпывающими данными о результатах измерений, и алгоритма их анализа и интерпретации» $[2,48]$

Во-вторых, индивидуальные образовательные траектории, карты, маршруты также невозможны без первоначальной педагогической диагностики, чтобы определять ресурсы, средства и методы обучения и воспитания. Поэтому в качестве основной особенности информационных технологий в педагогической диагностике следует отметить их личностную ориентированность, комплексность методов их технологий, и главное - вариативное содержание, которое зависит не только от целей и кри- териев диагностики, но и от педагогических особенностей обучающихся. Несомненно, основное место в информационных технологиях отводится компьютерным, мультимедийным технологиям, которые позволяют наглядно и доступно представить сложные диагностические методики и затем их обработать. Это немаловажно, т.к. позволяет экономить время исследователей, повышает доступность диагностики для различных категорий обучающихся, а также повышает эффективность ее усвоения.

В частности, С.Л. Новоселова рассматривает понятие мультимедиа «как возможность с помощью компьютера предоставлять информацию пользователю через все возможные виды данных, такие как аудио, видео, мультипликация, изображение и другие в дополнение к традиционным способам предоставления информации, таким как текст». [5, 52]

С конца прошлого столетия информационные технологии начали внедряться в педагогическую практику за рубежом. «В результате изучения вопросов развития информационных технологий в странах Европы, США, Канады выяснено, что они имеют приоритетные особенности: достигнуто внедрение медиа-образования путем достижения интеграции между учебными дисциплинами» $[4,16]$ Затем немного позже в отечественных исследованиях также начало актуализироваться включение информационных технологий в педагогический процесс. Сочетание концептуальных основ педагогической науки и тенденций информатизации общества позволяет обеспечить эффективность той педагогической системы, которая подвергается воздействию - образовательное или воспитательное пространство, индивидуальная или групповая диагностика не только в плане содержания, но и глубины, полноты диагностических критериев, их учета для построения и корректировки педагогического процесса.

Внедрение информационных технологий в процесс педагогической диагностики позволяет обеспечить более точные результаты, и в соответствии с ними, более правильно разработать образовательную либо воспитательную технологию. Кроме того, это позволяет придать диагностике развивающий аспект, т.к. способствует развитию проективных способностей обучающихся, развитию мотивации достижения и результативности, а также повышает воспитательный эффект образования. Современное общество со сложной инфраструктурой, объемом информации, глобальными тенденциями развития, предъявляет качественно новые требования к человеку как личности и профессионалу. Сложно развивать предметные и межпредметные компетенции специалиста или обучающегося, не выявив его склонности, интересы, личностные особенности, профессиональную направленность, а также социальную ситуацию развития. 
Информационные технологию позволяют максимально полно и быстро собирать данные, необходимые для построения педагогического процесса, выявлять степень адаптивности к информационным нагрузкам, объему материала, выявлять педагогические особенности обучающихся.

Применение информационных технологий в педагогической диагностике позволяет не только определить уровень диагностируемых параметров, но и принимать рациональные и эффективные решения по моделированию и реализации педагогического процесса, а также спрогнозировать результат педагогического воздействия при различных вариантах развития ситуации. Полученную информацию после обработки возможно передавать различным специалистам в удобном для них формате, также проводить фронтальную диагностику и сравнительный анализ по различным параметрам и в динамике.

Исходя из вышесказанного, необходимо подвести итоги нашего исследования. В ходе работы была достигнута цель - определена специфика информационных технологий в педагогической диагностике, которая заключается в разработке личностно ориентированных и включающих максимально полный «набор» критериев средств и технологий диагностики. При этом технологии должны позволять обобщать, сравнивать, противопоставлять данные, а также представлять их при помощи технических средств информатизации.

Также были решены основные задачи исследования. Во-первых, определено содержания информационных технологий в педагогической диагностике. Основной особенностью педагогической диагностики является ее системность и личностно ориентированная направленность «Система педагогической диагностики, предназначенная для создания рекомендаций для оптимизации учебного процесса, производит соответствующие рекомендации для себя и реализует их, совершенствуя свою структуру, связи управления, алгоритмы и средства диагностирования, базовые модели студента и содержания обучения, систему классификации и методику прогнозирования». [3, 480] в содержание информационных технологий диагностики необходимо включать мультимедийные средства, которые позволят сделать диагностический процесс более комфортным, эффективным для обследуемых, а исследователю оставить максимум времени для качественного анализа, используя полученные количественные данные.

Во-вторых, была выявлена необходимость включения информационных технологий в педагогическую диагностику. Данный факт обусловлен необходимостью получения более точных, зачастую крупномасштабных данных с большими объемами диагностических пара- метров и применением сложных, многофакторных диагностик, которые сложны и ресурснозатратны в обработке. Информационные технологии позволяют сделать процесс количественной обработки более быстрым и сосредоточить усилия на качественном анализе полученной информации. Безусловно, качество диагностики зависит от многих критериев- в частности, от объема и характеристик выборки, определения методик работы, целей диагностики и совокупности иных объективных и субъективных факторов. Однако, одной из основных особенностей информационных технологий является, с одной стороны - их стандартизированный характер, с другой- личностно ориентированная направленность.

В-третьих, нами было актуализировано использование информационных технологий в педагогической диагностике. Оно отражается в мировых тенденциях развития общества- информатизации, цифровизации, масштабирования дистанционных форм работы, коммуникации и образования. Информационные компетенции являются ключевыми в результатах образования и критериях приема на работу специалистов. В. Хутмахер, выступая с докладом в Берне, «выделил пять ключевых компетенций, которыми должны обладать молодые европейцы, среди которых «компетенции, связанные с информатизацией общества, владение этими технологиями» $[1,84]$

Информационные технологии в педагогической диагностике позволяют определить, и в дальнейшем корректировать педагогический процесс, варьировать его содержание в зависимости от полученных результатов. При этом очень важно проводить точную диагностику через определенный промежуток времени, отражая динамику развития диагностических параметров в соответствии с принципами индивидуального подхода и целеполагания в условиях коллективной учебной или воспитательной деятельности.

По мнению Колгатина А.Г., система информатизации педагогической диагностики должна позволять отслеживать распределение определенных педагогических характеристик в группе исследуемых либо динамику диагностируемых параметров при индивидуальной диагностике. «Объективное измерение знаний и способностей, возможность их сравнения с распределением соответствующих параметров в студенческом кругу и среди других людей соответствующего возраста способствует формированию объективной самооценки» [3, 485] Немаловажное значение информационные технологии имеют и при контрольной диагностике, когда необходимо выявить динамику диагностируемых параметров, определить проблемные зоны образовательного либо воспитательного процесса и наметить перспективы развития той или иной педагогической системы. 


\section{ЛИТЕРАТУРА}

1. Воронов Сергей Алексеевич Структура и содержание компетенций в области использования информационно-коммуникационных технологий // Вестник ЧГПУ им. И.Я. Яковлева. 2017. №3-1 (95). URL: https://cyberleninka.ru/article/n/struktura-i-soderzhanie-kompetentsiy-v-oblasti-ispolzovaniya-informatsionnokommunikatsionnyh-tehnologiy (дата обращения: 13.05.2021).

2. Кирилова Г.И. Дидактические основы построения контроля знаний и умений в компьютерной технологии обучения: автореф. дис. на соиск. учен. степ. канд. пед. наук. Казань, 2014. 16 с.

3. Колгатин Александр Геннадиевич Проектирование компьютерно-ориентированной системы педагогической диагностики как педагогическая проблема // 0T0. 2012. №3. URL: https://cyberleninka.ru/article/n/proektirovanie-kompyuterno-orientirovannoy-sistemy-pedagogicheskoy-diagnostiki-kakpedagogicheskaya-problema (дата обращения: 11.05.2021).

4. Лутфиллаев Махмуд Хасанович, Абдуллаева Шахзода Абдуллаевна Вопросы разработки и внедрения программного обеспечения педагогической диагностики (на примере высших учебных заведений республики Узбекистан) // Образовательные ресурсы и технологии. 2019. №3 (28). URL: https:// cyberleninka.ru/article/n/voprosy-razrabotki-i-vnedreniya-programmnogo-obespecheniya-pedagogicheskoy-diagnostiki-na-primere-vysshih-uchebnyhzavedeniy (дата обращения: 11.05.202)

5. Оробинская А.Н. Мультимедиа-технологии и их использование в системе дошкольного обучения // Таврический научный обозреватель. 2016. №1-3 (6). URL: https://cyberleninka.ru/article/n/multimedia-tehnologii-i-ih-ispolzovanie-v-sisteme-doshkolnogo-obucheniуa (дата обращения: 11.05.2021).

6. Пеньковская Г.А., Сидина Т.А., Тараканова А.А. Роль информационно - коммуникационных технологий как инновационного аспекта в реализации ФГоС до // Вестник БГУ. 2014. №4-1. URL: https://cyberleninka.ru/article/n/rol-informatsionno-kommunikatsionnyh-tehnologiy-kak-innovatsionnogo-aspekta-vrealizatsii-fgos-do (дата обращения: 12.05.2021)

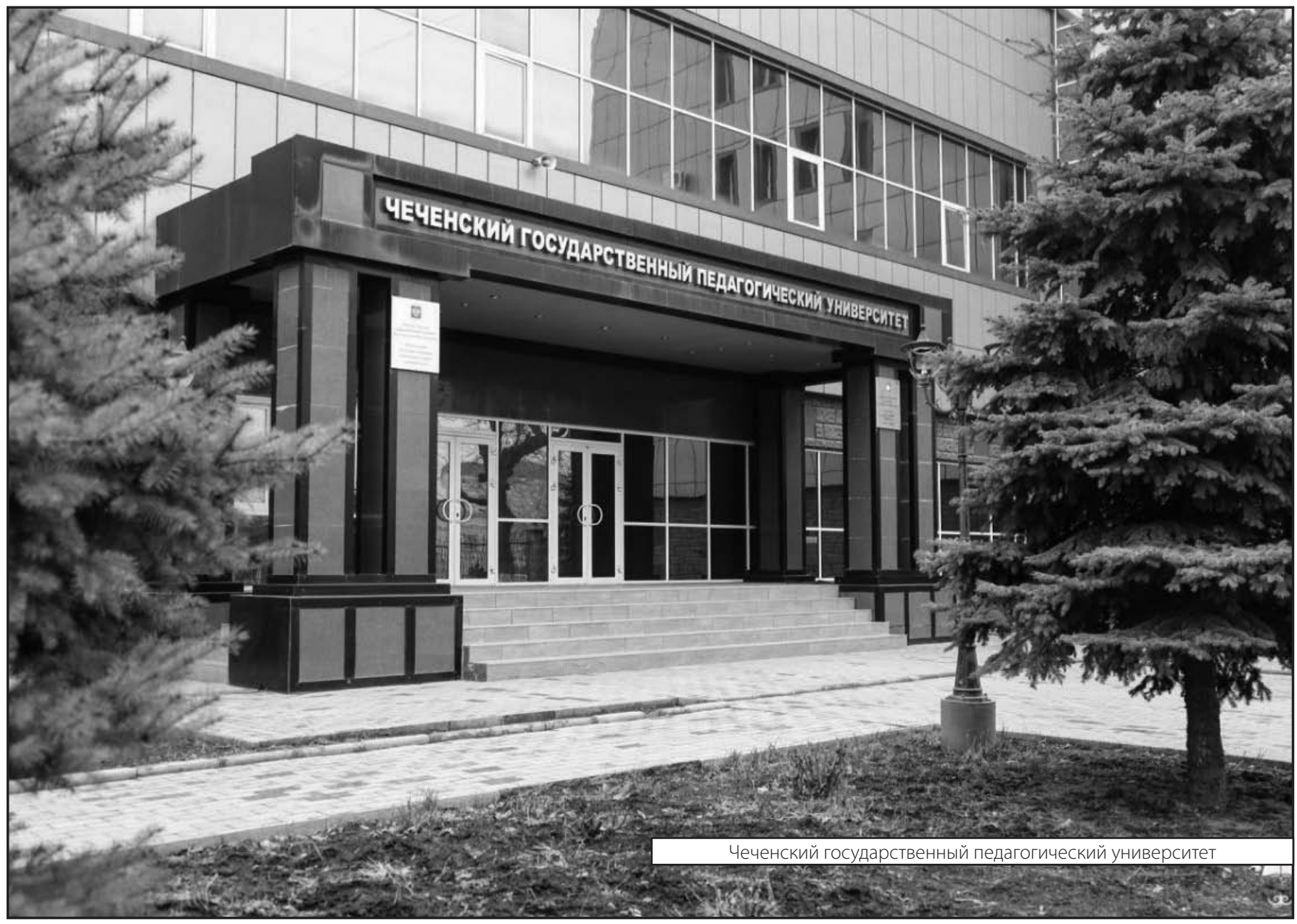

